\title{
The Resting Transducer Current Drives Spontaneous Activity in Prehearing Mammalian Cochlear Inner Hair Cells
}

\author{
Stuart L. Johnson, ${ }^{1}$ Helen J. Kennedy, ${ }^{2}$ Matthew C. Holley, ${ }^{1}$ Robert Fettiplace, ${ }^{3}$ and Walter Marcotti ${ }^{1}$ \\ ${ }^{1}$ Department of Biomedical Science, University of Sheffield, Sheffield S10 2TN, United Kingdom, ${ }^{2}$ School of Physiology and Pharmacology, University of \\ Bristol, Bristol BS8 1TD, United Kingdom, and ${ }^{3}$ Department of Neuroscience, University of Wisconsin Medical School, Madison, Wisconsin 53706
}

\begin{abstract}
Spontaneous $\mathrm{Ca}^{2+}$-dependent electrical activity in the immature mammalian cochlea is thought to instruct the formation of the tonotopic map during the differentiation of sensory hair cells and the auditory pathway. This activity occurs in inner hair cells (IHCs) during the first postnatal week, and the pattern differs along the cochlea. During the second postnatal week, which is before the onset of hearing in most rodents, the resting membrane potential for IHCs is apparently more hyperpolarized (approximately $-75 \mathrm{mV}$ ), and it remains unclear whether spontaneous action potentials continue to occur. We found that when mouse IHC hair bundles were exposed to the estimated in vivo endolymphatic $\mathrm{Ca}^{2+}$ concentration $(0.3 \mathrm{mM})$ present in the immature cochlea, the increased open probability of the mechanotransducer channels caused the cells to depolarize to around the action potential threshold (approximately $-55 \mathrm{mV}$ ). We propose that, in vivo, spontaneous $\mathrm{Ca}^{2+}$ action potentials are intrinsically generated by IHCs up to the onset of hearing and that they are likely to influence the final sensory-independent refinement of the developing cochlea.
\end{abstract}

\section{Introduction}

Spontaneous electrical activity that occurs during critical periods of immature development drives the refinement of neuronal circuits in sensory organs before the onset of sensory experience (Blankenship and Feller, 2010). In the mammalian auditory system, $\mathrm{Ca}^{2+}$ action potentials occur spontaneously in inner hair cells (IHCs), the primary auditory sensory receptors, before the onset of hearing (Kros et al., 1998; Johnson et al., 2011a). In altricial rodents hearing onset corresponds to postnatal day 12 (P12). Spontaneous activity in IHCs appears to be confined to the first postnatal week of development, and its pattern differs along the cochlea as the tonotopic frequency map develops (Marcotti et al., 2003a; Johnson et al., 2011a). Since this early spiking is able to trigger the exocytosis of synaptic vesicles at IHC ribbon synapses (Beutner and Moser, 2001; Marcotti et al., 2003b), it could potentially drive the remodeling of auditory neural circuits in the brainstem, which occurs during this time window (Kandler et al., 2009).

The apparent disappearance of spontaneous IHC activity from the beginning of the second postnatal week is caused by progressive hyperpolarization of the resting membrane potential down to approximately $-75 \mathrm{mV}$ (Kros et al., 1998; Johnson et al., 2011a), which is below the activation of the $\mathrm{Ca}^{2+}$ current (Johnson and Marcotti, 2008; Zampini et al., 2010). Therefore, it has

\footnotetext{
Received Feb. 20, 2012; revised June 6, 2012; accepted June 7, 2012.

Author contributions:S.L.J., R.F., and W.M. designed research;S.L.J., H.J.K., and W.M. performed research; S.L.J., H.J.K., and W.M. analyzed data; S.L.J., M.C.H., R.F., and W.M. wrote the paper.

This work was supported by the Wellcome Trust (Grants 088719 and 091895 to W.M.; Grant 072809 to H.J.K.) and

by NIDCD Grant R01 DC013672 to R.F. W.M. and S.L.J. are Royal Society University Research Fellows.

This article is freely available online through the J Neurosci Open Choice option.

Correspondence should be addressed to either Walter Marcotti or Stuart Johnson at the above address. E-mail: w.marcotti@sheffield.ac.uk or s.johnson@sheffield.ac.uk.

DOI:10.1523/JNEUROSCI.0803-12.2012

Copyright $\odot 2012$ the authors $\quad 0270-6474 / 12 / 3210479-05 \$ 15.00 / 0$
}

been proposed that in these older IHCs action potentials are not spontaneous but instead require membrane depolarization caused by periodic release of ATP from adjacent supporting cells (Tritsch et al., 2007). However, recent recordings under in vivolike conditions showed that the membrane potential $\left(V_{\mathrm{m}}\right)$ of adult IHCs is more positive (near $-60 \mathrm{mV}$; Johnson et al., 2011b) than that previously suggested (near $-75 \mathrm{mV}$; Kros et al., 1998). This is because a crucial factor in determining the $V_{\mathrm{m}}$ is the depolarizing, resting, inward mechanotransducer current, which has not been taken into account in earlier work. In this study, we propose that the magnitude of $V_{\mathrm{m}}$ in these older IHCs has been significantly overestimated and that spontaneous electrical activity is present up to the onset of hearing, whereupon it ceases due to the expression of a very rapidly activating large conductance calcium-activated potassium current (Kros et al., 1998).

\section{Materials and Methods}

Electrophysiology. Apical and basal coil IHCs from mice (of either sex) were studied in acutely dissected organs of Corti from P7 to P10, where the day of birth is P0. Mice were killed by cervical dislocation in accordance with United Kingdom Home Office regulations. Cochleae were dissected in the following normal extracellular solution (in $\mathrm{mm}$ ): 135 $\mathrm{NaCl}, 5.8 \mathrm{KCl}, 1.3 \mathrm{CaCl}_{2}, 0.9 \mathrm{MgCl}_{2}, 0.7 \mathrm{NaH}_{2} \mathrm{PO}_{4}, 5.6 \mathrm{D}$-glucose, and 10 HEPES-NaOH. Sodium pyruvate $(2 \mathrm{~mm})$, MEM amino acids solution $(50 \times$, without L-glutamine) and MEM vitamins solution $(100 \times)$ were added from concentrates (Fisher Scientific). The $\mathrm{pH}$ was adjusted to 7.5 (osmolality $\sim 308 \mathrm{mmol} \mathrm{kg}^{-1}$ ).

Whole-cell patch-clamp recordings were performed at body temperature $\left(34-37^{\circ} \mathrm{C}\right)$ using an Optopatch (Cairn Research Ltd) or Axon 200B (Molecular Devices) amplifiers. Patch pipettes (2-3 M $\Omega$ ) contained the following (in mM): $131 \mathrm{KCl}, 3 \mathrm{MgCl}_{2}, 5 \mathrm{Na}_{2} \mathrm{ATP}, 10 \mathrm{Na}_{2}-$ phosphocreatine, 1 EGTA, 5 HEPES, pH 7.3 (293 mOsmol kg-1). Perforated-patch was also used in a few experiments performed at $34-$ $37^{\circ} \mathrm{C}$, and the pipette filling solution contained the following (in $\mathrm{mM}$ ): $103 \mathrm{~K}$-aspartate, $21 \mathrm{KCl}, 3 \mathrm{MgCl}_{2}, 5 \mathrm{Na}_{2} \mathrm{ATP}, 5$ EGTA, 5 HEPES-KOH, 
$10 \mathrm{Na}_{2}$-phosphocreatine, pH $7.3(295 \mathrm{mmol}$ $\left.\mathrm{kg}^{-1}\right)$. The antibiotic amphotericin B (Merck) was dissolved in dry DMSO before dilution in the above intracellular solution to $240 \mu \mathrm{g} \mathrm{ml}^{-1}$ (Johnson et al., 2007). Data acquisition was controlled by pClamp software using Digidata 1322 and 1440A boards (Molecular Devices). Recordings were low-pass filtered at $2.5 \mathrm{kHz}$ (8-pole Bessel) and sampled at $5 \mathrm{kHz}$. Data analysis was performed using Origin software (OriginLab). Membrane potentials were corrected for a liquid junction potential measured between electrode and bath solutions, using measured values of $-4 \mathrm{mV}$ for the $\mathrm{KCl}$-based and $-11 \mathrm{mV}$ for the K-aspartate-based intracellular solutions. Statistical comparisons of means were made by Student's two-tailed $t$ test. Values are given as the mean \pm SEM, and $p<$ 0.05 indicates statistical significance.

Confocal calcium imaging was performed from P10 IHCs using an Olympus Fluoview 300 confocal microscope. Fluo-4 $(100 \mu \mathrm{M})$ was loaded through the patch pipette, and dye was excited with $488 \mathrm{~nm}$ light and emission $>510$ $\mathrm{nm}$ collected by a photon multiplier tube. Optical sections were $\sim 0.5 \mu \mathrm{m}$ thick. Analysis was of a band of nominally $1 \mu \mathrm{m}$ width. Line scan collection speed was $1.808 \mathrm{~ms}$ per line, and the analysis was averaged by 2 to reduce noise so each point represents $3.6 \mathrm{~ms}$. Image analysis was done in Igor Pro 6.0 and ImageJ.

Mechanoelectrical transducer currents were elicited by stimulating the hair bundles of P7-P9 IHCs using a fluid jet from a pipette (tip diameter $8-10 \mu \mathrm{m}$ ) driven by a piezoelectric disc (Kros et al., 1992; Marcotti et al., 2005). The pipette tip of the fluid jet was positioned near to the bundles to elicit a maximal transducer current. Saturating mechanical stimuli were applied as $50 \mathrm{~Hz}$ sinusoids (filtered at $0.25 \mathrm{kHz}, 8$-pole Bessel) with driving voltages of $\pm 40 \mathrm{~V}$. The effects of endolymph on the mechanotransducer current were investigated by superfusing a $\mathrm{Na}^{+}$-based extracellular solution containing $0.3 \mathrm{mM} \mathrm{Ca}^{2+}$, which was also used to fill the fluid jet pipette. $\mathrm{A} \mathrm{Na}^{+}$-based solution was preferred to the $\mathrm{K}^{+}$-based solution, normally present in the endolymph, to avoid IHC depolarization due to possible leak of high $\mathrm{K}^{+}$toward the cell body. A similar method has recently been used to stimulate cochlear outer hair cells and showed that substituting $\mathrm{Na}^{+}$for $\mathrm{K}^{+}$has no significant effect on the fraction of mechanotransducer current activated at rest (Johnson et al., $2011 \mathrm{~b})$. The $\mathrm{Ca}^{2+}$ concentration in the endolymph-like solution $(0.287 \pm 0.002 \mathrm{~mm}, n=4)$ was calibrated using a $\mathrm{Ca}^{2+}$ ion-selective electrode (Scientific Laboratories Supplies) using standard solutions (0.0001, 0.001, 0.01, and $0.1 \mathrm{M} \mathrm{Ca}^{2+}$ : average difference between each tenfold increase in $\mathrm{Ca}^{2+}$ was $29.5 \pm 0.2 \mathrm{mV}$ from four sets of calibrations). Superfusion of $0.2 \mathrm{~mm}$ dihydrostreptomycin (DHS) was used to establish the fraction and size of the resting mechanotransducer current (Marcotti et al., 2005). Mechanotransducer currents were recorded with a patch pipette solution containing 1 mM EGTA as the calcium buffer, which was previously assessed using perforated patch recordings (Johnson et al., 2008).

Continuous superfusion of IHCs with extracellular solutions with or without drugs [trinitrophenyl (TNP)-ATP (an antagonist for purinergic P2X receptors), Tocris Bioscience; strychnine ( $\alpha 9 \alpha 10$ nAChR blocker), Sigma; DHS (a mechanoelectrical transducer channel blocker), Sigma] or with low $\mathrm{Ca}^{2+}$ was achieved using a multibarrelled pipette positioned a few millimeters from the tissue and perpendicular to the direction of hair bundle sensitivity, such that the flow of solution did not cause any hair bundle movement.

Estimation of endolymphatic $\mathrm{Ca}^{2+}$ concentration in the immature cochlea. Stereociliary bundles of adult hair cells are normally surrounded by endolymph, which is high in $\mathrm{K}^{+}(\sim 150 \mathrm{~mm}$; Wangemann and Schacht, $1996)$ and low in $\mathrm{Ca}^{2+}(\sim 20 \mu \mathrm{M}$ in the adult; Bosher and Warren, 1978).
B
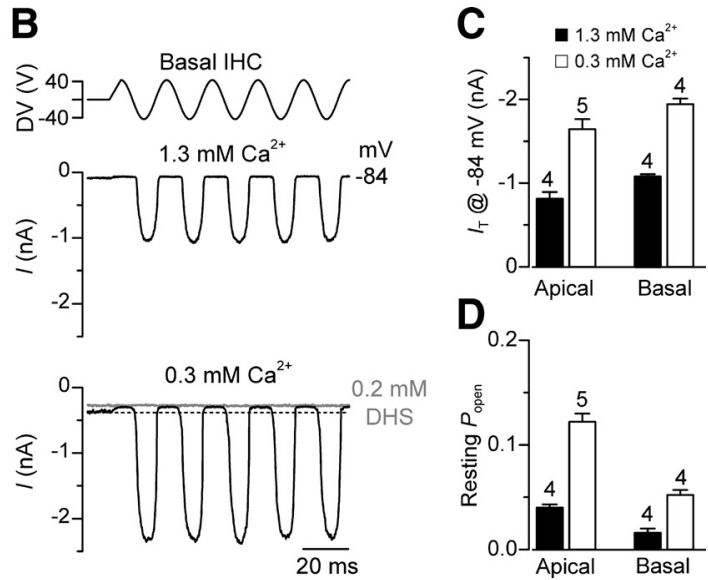

\section{$\overline{20 \mathrm{~ms}}$}

Figure 1. Mechanoelectrical transducer current in cochlear IHCS.A, B, Saturating mechanotransducer currents recorded from an bottom). The driver voltage (DV) signal to the fluid jet is shown above the traces (positive deflection of the DV is inhibitory). Note that mechanotransducer current amplitude was larger and its fraction activated at rest was increased in the presence of stimulus, indicated by the dashed line, and the current level on the negative phase of the stimulus when all channels were closed) by the maximum peak-to-peak mechanotransducer current.

This differs from the perilymph surrounding the basolateral membrane, which contains high $\mathrm{Na}^{+}(\sim 150 \mathrm{~mm})$ and $\mathrm{Ca}^{2+}(1.3 \mathrm{~mm})$ (Wangemann and Schacht, 1996). However, in rodents, the ionic composition of the endolymph and perilymph is similar at birth (Wangemann and Schacht, 1996). The endolymphatic $\mathrm{Ca}^{2+}$ concentration is partly determined by a passive distribution between the endolymph and perilymph (Bosher and Warren, 1978; Ikeda and Morizono, 1989). This passive component can be calculated from the Nernst equation, $V_{\mathrm{EP}}=30 \log _{10}\left(\mathrm{Ca}_{p} / \mathrm{Ca}_{e}\right)$, where $\mathrm{Ca}_{p}$ and $\mathrm{Ca}_{e}$ are the $\mathrm{Ca}^{2+}$ concentrations in the perilymph and endolymph, respectively, and $V_{\mathrm{EP}}$ is the endocochlear potential. The passive component in the adult cochlea, in which $V_{\mathrm{EP}}=90 \mathrm{mV}$, should make $\mathrm{Ca}_{e} 1.3 \mu \mathrm{M}$, but the measured concentration is $\sim 20 \mu \mathrm{M}$. The difference is thought to reflect active pumping of $\mathrm{Ca}^{2+}$ into the scala media by outer hair cells (Wood et al., 2004). However, the endocochlear potential is very small during the first postnatal week and only $\sim 20 \mathrm{mV}$ during the second postnatal week (P8-P11) (Bosher and Warren, 1971). The $\mathrm{Ca}_{e}$ due to passive distribution in younger IHCs (P8-P12) is thus $0.28 \mathrm{mM}$, which, summed to that of the active mechanism ( $19 \mu \mathrm{M})$, gives an estimated endolymphatic $\mathrm{Ca}^{2+}$ concentration of $\sim 0.3 \mathrm{~mm}$. During the first postnatal week, the estimated $\mathrm{Ca}^{2+}$ concentration in the endolymph remains very similar to the perilymph (i.e., in the millimolar range).

\section{Results}

Mechanoelectrical transducer currents recorded in immature IHCs using an endolymph-like $\mathrm{Ca}^{2+}$ concentration

Mechanotransducer currents were elicited by displacing IHC hair bundles with alternating inhibitory and excitatory displacement using a $50 \mathrm{~Hz}$ sinusoidal force stimulus (Marcotti et al., 2005). A large inward transducer current was elicited upon moving the bundle in the excitatory direction (i.e., toward the taller stereocilia) (Fig. $1 A, B$ ). Superfusion of the IHC hair bundles with a solution containing an endolymph-like $\mathrm{Ca}^{2+}$ concentration $(0.3$ $\mathrm{mM}$ in prehearing IHCs; see Materials and Methods), instead of perilymph-like $1.3 \mathrm{mM} \mathrm{Ca}^{2+}$, caused a significant $(p<0.001)$ increase in the mechanotransducer current amplitude in both apical (1.3 mM: $0.81 \pm 0.08 \mathrm{nA}, n=4 ; 0.3 \mathrm{mm:} 1.64 \pm 0.12 \mathrm{nA}$, $n=5)$ and basal ( $1.3 \mathrm{~mm}: 1.08 \pm 0.03 \mathrm{nA}, n=4 ; 0.3 \mathrm{mm:} 1.94 \pm$ $0.07 \mathrm{nA}, n=4$ ) cells during the second postnatal week (Fig. 1C). 

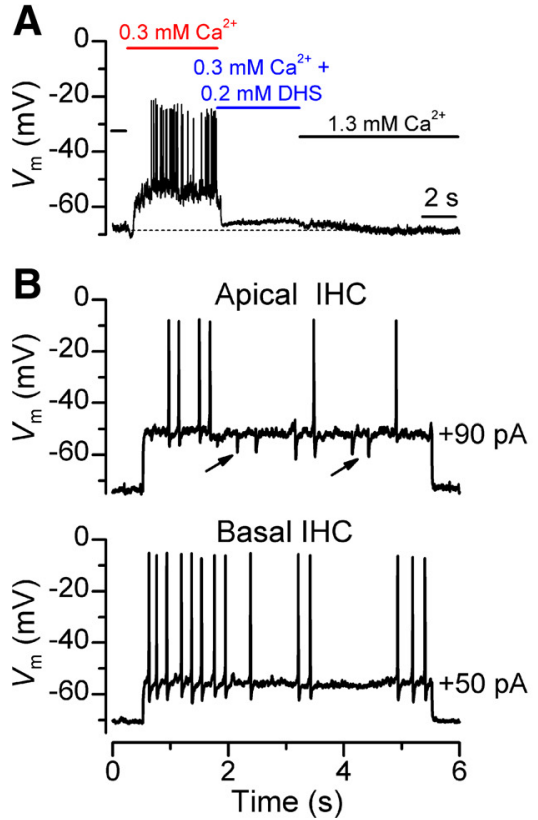
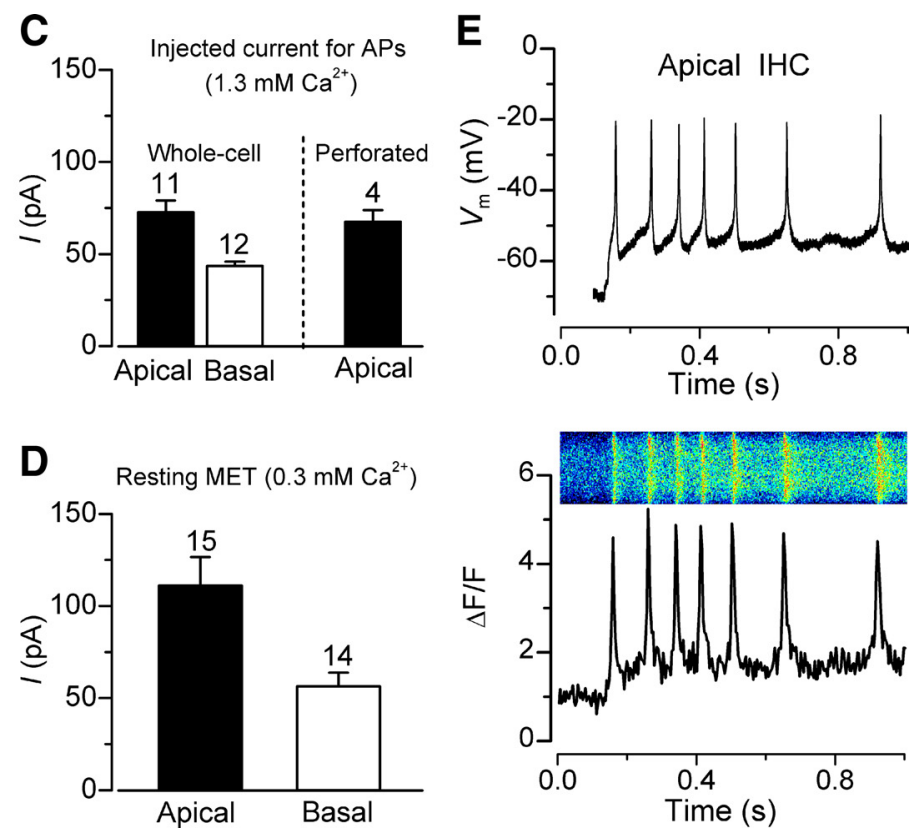

Figure 2. Action potential activity in second-postnatal week IHCS.A, IHC voltage responses recorded during the superfusion of $1.3 \mathrm{~mm} \mathrm{Ca}^{2+}$ or $0.3 \mathrm{~mm} \mathrm{Ca}^{2+}$ alone or together with DHS. B, Action potentials elicited from an apical (top) and a basal (bottom) IHC during depolarizing current injection in $1.3 \mathrm{~mm} \mathrm{Ca}{ }^{2+}$. Arrows indicate IPSPs. C, Average current amplitude required to depolarize apical (whole-cell and perforated patch recordings) and basal (whole-cell recordings) IHCs to trigger action potential activity in $1.3 \mathrm{~mm} \mathrm{Ca}{ }^{2+}$. D, Average resting mechanotransducer current in apical and basal IHCs in $0.3 \mathrm{~mm} \mathrm{Ca}{ }^{2+}$. This was obtained at $-70 \mathrm{mV}$, which matches the IHC resting membrane potential in $1.3 \mathrm{~mm} \mathrm{Ca}^{2+}$. E, Simultaneous recording of induced action potential activity (top) and calcium transients (bottom) in an apical IHC. Minimum current injection was used to reach spike threshold. The $\mathrm{Ca}^{2+}$ image was taken across the base of the IHC and has been smoothed in ImageJ.

Extracellular $\mathrm{Ca}^{2+}$ is a known permeant blocker of the mechanotransducer channel (Ricci and Fettiplace, 1998; Marcotti et al., 2005), so the increased current amplitude in low $\mathrm{Ca}^{2+}$ is caused by the partial relief of this block. The presence of low endolymphatic $\mathrm{Ca}^{2+}$ also increased the resting mechanotransducer current flowing through open mechanotransducer channels in the absence of mechanical stimulation. This current was attributed to the mechanotransducer channels since it was reduced when bundles were moved in the inhibitory direction (i.e., away from the taller stereocilia) (Fig. 1A,B) and completely abolished in the presence of $0.2 \mathrm{~mm}$ DHS (Fig. $1 A, B$ ), a known blocker of the mechanotransducer channel (Marcotti et al., 2005). The increased resting mechanotransducer current in low $\mathrm{Ca}^{2+}$ is also consistent with a leftward shift in the current-displacement relationship due to a reduction in the $\mathrm{Ca}^{2+}$-dependent adaptation of the mechanotransducer channel (Ricci and Fettiplace, 1998) such that more channels remain open. The open probability of mechanotransducer channels at rest in endolymphatic $\mathrm{Ca}^{2+}$ was significantly $(p<0.0001)$ larger in apical $(0.12 \pm 0.01, n=5)$ than basal $(0.05 \pm 0.01, n=4)$ IHCs (Fig. $1 D)$. The larger mechanotransducer current in low $\mathrm{Ca}^{2+}$ would tend to depolarize the membrane potential of immature IHCs making them more likely to generate spontaneous electrical activity.

\section{Action potential activity in developing IHCs}

Spontaneous spiking activity has only been observed during the first postnatal week (Beutner and Moser, 2001; Marcotti et al., $2003 b$ ). From the second postnatal week, the spontaneous activity of IHCs in isolated tissue preparations apparently disappears (Marcotti et al., 2003a), which is correlated with a progressive hyperpolarization of the resting $V_{\mathrm{m}}$. However, the experimental data behind this interpretation were based on recordings from IHCs using perilymph-like solution $\left(\geq 1.3 \mathrm{mM} \mathrm{Ca}^{2+}\right)$. Therefore, we have re-evaluated the possibility that action potentials are spontaneously generated by IHCs throughout postnatal immature development using the estimated endolymphatic $\mathrm{Ca}^{2+}$ concentration of $0.3 \mathrm{~mm}$.

When the hair bundles of IHCs from the second postnatal week were superfused with $0.3 \mathrm{mM} \mathrm{Ca}^{2+}$, cells depolarized and fired spontaneous action potentials. However, this depolarization tended to exceed that required to reach spike threshold and did not fully reverse to that of $1.3 \mathrm{mM} \mathrm{Ca}^{2+}$ in the presence of DHS (Fig. 2A), indicating that a small part of the depolarization was not related to the mechanotransducer current. The DHSinsensitive depolarization could be caused by some "leak" of the low $\mathrm{Ca}^{2+}$ solution toward the cell body via the small hole created to gain access with the patch pipette. Although this would not occur in vivo, due to the compartmentalization provided by the reticular lamina, it prevented us from directly determining the effect of a larger resting transducer current in low endolymphatic $\mathrm{Ca}^{2+}$ on IHC $V_{\mathrm{m}}$. Any attempt to pharmacologically eliminate this DHS-insensitive component would have an undesirable effect on the IHC resting membrane potential and spiking activity. Therefore, we compared the size of the depolarizing current provided by the resting mechanotransducer current (DHS-sensitive current) in low-endolymph-like $\mathrm{Ca}^{2+}$ (Fig. $1 D$ ) to that required to elicit action potentials in P8-P9 IHCs using $1.3 \mathrm{mM} \mathrm{Ca}^{2+}$ (Fig. $2 B$ ). In accordance with previous findings (Marcotti et al., 2003a), the $V_{\mathrm{m}}$ of IHCs when their hair bundles were exposed to $1.3 \mathrm{mM} \mathrm{Ca}^{2+}$ (whole-cell: apical $-70.8 \pm 0.9 \mathrm{mV}, n=11$; basal $-70.4 \pm 0.8 \mathrm{mV}, n=12$; perforated patch: apical $-73.6 \pm 2.4$ $\mathrm{mV}, n=4$ ) was negative to the threshold required to elicit spontaneous action potentials (whole-cell: apical $-53.7 \pm 0.5 \mathrm{mV}$, $n=11$; basal $-55.4 \pm 1.1 \mathrm{mV}, n=12$; perforated patch: apical $-54.1 \pm 1.2 \mathrm{mV}, n=4$ ) (Fig. $2 \mathrm{~B}$ ). The depolarizing current required to reach the spike threshold was significantly larger in apical (whole-cell: $72.7 \pm 6.4 \mathrm{pA}, n=11$; perforated patch $70.0 \pm$ $7.1 \mathrm{pA}, n=4$ ) than in basal (whole-cell: $42.5 \pm 2.4 \mathrm{pA}, n=12$ : 
$p<0.001$ and $p<0.05$, respectively) IHCs (Fig. 2C). These values fit well with the depolarizing current provided by the resting mechanotransducer channel in endolymphatic $0.3 \mathrm{~mm} \mathrm{Ca}^{2+}$ (Fig. 1) in both apical (111.2 $\pm 15.4 \mathrm{pA}, n=15)$ and basal (56.4 \pm $7.5 \mathrm{pA}, n=14$ ) IHCs (Fig. 2D). The resting mechanotransducer current would be somewhat augmented in vivo by the presence of the $20 \mathrm{mV}$ endolymphatic potential, which would further depolarize the IHCs.

The above findings indicate that both apical and basal IHCs would be likely to fire spontaneous action potentials in vivo. For these experiments, it was not possible to quantify whether differences in the pattern of action potential activity between apical and basal IHCs were present as previously described for younger cells (Johnson et al., 2011a). This is because it is extremely difficult to maintain stability of the IHC $V_{\mathrm{m}}$ for long periods of time when injecting depolarizing currents in whole-cell recordings, which is required for the analysis of spiking activity. Finally, we combined electrophysiological recordings with $\mathrm{Ca}^{2+}$ imaging in P10 IHCs (Fig. 2E) and showed that action potentials induced by current depolarization are able to generate $\mathrm{Ca}^{2+}$ transients, which are essential for controlling neuronal differentiation (Spitzer et al., 2000). We also found that IHCs during the second postnatal week remained responsive to endogenous ATP and $\mathrm{ACh}$, as recently shown for younger mouse IHCs (Johnson et al., 2011a), since the superfusion of $10 \mu \mathrm{M}$ TNP-ATP or $1 \mu \mathrm{M}$ strychnine caused them to depolarize (TNP-ATP: $3.5 \pm 0.2 \mathrm{mV}, n=27$; strychnine: $1.4 \pm 0.2 \mathrm{mV}, n=3$ ) and reversibly increased the action potential frequency when cells were depolarized in current-clamp to spike threshold.

\section{Discussion}

In this study, we determined that the resting $V_{\mathrm{m}}$ in IHCs, at body temperature and with an estimated in vivo endolymph-like $\mathrm{Ca}^{2+}$ concentration, is likely to reside around the action potential threshold during the second postnatal week of development. We found that under these physiological conditions the increased resting mechanotransducer current was capable of driving spontaneous action potential activity in IHCs. This suggests that spontaneous firing activity is not restricted to the first postnatal week (Marcotti et al., 2003b; Johnson et al., 2011a).

A crucial factor determining the level of spiking activity in immature IHCs is their resting $V_{\mathrm{m}}$ (Marcotti et al., 2003a), which in vivo is largely determined by the balance between an inward, depolarizing resting mechanotransducer current and outward voltage-dependent $\mathrm{K}^{+}$currents (Johnson et al., 2011b). Although the mechanotransducer apparatus seems fully functional from the second postnatal week (Lelli et al., 2009), the ionic composition of the endolymph, which is essential for the function of the mechanotransducer channels, remains immature (Rübsamen and Lippe, 1998). Previous studies that have used $1.3 \mathrm{mM} \mathrm{Ca}^{2+}$ (Beutner and Moser, 2001; Marcotti et al., 2003a) showed that $V_{\mathrm{m}}$ for IHCs becomes more hyperpolarized during development so that spontaneous action potentials no longer occur during the second postnatal week (Marcotti et al., 2003a). In this study, we calculated that during the second postnatal week the mechanotransducer channels of IHCs are likely to be exposed to an endolymphatic solution containing $0.3 \mathrm{~mm} \mathrm{Ca}^{2+}$. Because the fraction of mechanotransducer channels open at rest is determined by their $\mathrm{Ca}^{2+}$-driven adaptation properties (Ricci and Fettiplace, 1998), the exposure to physiologically low $\mathrm{Ca}^{2+}$ results in a larger sustained depolarizing current that brings the $V_{\mathrm{m}}$ to around the threshold for spontaneous action potential activity. It is interesting that apical IHCs had a larger resting mechano- transducer current than basal cells, the size of which correlated with that required to elicit action potentials in both regions. This indicates that the biophysical properties of the IHC basolateral membrane are likely to have compensated for tonotopic differences in the mechanotransducer channels to keep the $V_{\mathrm{m}}$ near to the spike threshold, emphasizing the importance of maintaining spontaneous activity throughout immature development.

Recently, we have shown that during the first postnatal week, IHCs exhibit tonotopic differences in the frequency and pattern of spontaneous firing activity, which is modulated extracellularly both by the efferent neurotransmitter ACh and by ATP released from supporting cells (Johnson et al., 2011a). The persistence of these mechanisms in the second postnatal week, which was indicated by the effects of TNP-ATP and strychnine, suggests that extracellular control of the firing activity is not restricted to a small window during postnatal immature development. Therefore, these data further support the idea that ATP released from supporting cells, although not required for generating spontaneous action potential activity, could be important for modulating or coordinating electrical activity in IHCs during the second postnatal week (Tritsch et al., 2007).

Although IHCs are not required for the survival of adult auditory nerve fibers (Zilberstein et al., 2012), early electrical activity could be crucial to promote reorganization of synaptic connections along the auditory pathway during development, the majority of which is complete by the end of the first postnatal week (Kandler et al., 2009). From the second postnatal week the intrinsic electrical activity could have a more direct role on the functional development of the IHCs at the onset of hearing, which involves the acquisition and/or elimination of different combinations of ion channels and other membrane proteins (Marcotti, 2012). This is suggested by the observation that disrupting the structure and function of the mechanotransducer apparatus, such as that involving the deafness gene Myo6 (Self et al., 1999; Marcotti et al., 2001), causes a general failure in the normal maturation of IHCs (Heidrych et al., 2009). Any reduction of resting mechanotransducer current during the second postnatal week could keep IHCs hyperpolarized and therefore unable to fire action potentials in vivo. Despite the identification of several other deafness genes that cause mechanotransducer current abnormalities (e.g., Myo7a, MyoXVa) (Petit and Richardson, 2009), there is currently no information on whether the IHCs are able to mature normally. The late postnatal firing activity in immature IHCs, together with any patterning or coordination of firing in adjacent cells provided by extracellular waves of ATP (Tritsch et al., 2007), could also be important for the refinement of monaural sensory maps or the integration of binaural inputs in auditory brainstem nuclei before the onset of sound induced activity (Kandler et al., 2009).

\section{References}

Beutner D, Moser T (2001) The presynaptic function of mouse cochlear inner hair cells during development of hearing. J Neurosci 21:4593-4599.

Blankenship AG, Feller MB (2010) Mechanisms underlying spontaneous patterned activity in developing neural circuits. Nat Rev Neurosci 11:18-29.

Bosher SK, Warren RL (1971) A study of the electrochemistry and osmotic relationships of the cochlear fluids in the neonatal rat at the time of the development of the endocochlear potential. J Physiol 212:739-761.

Bosher SK, Warren RL (1978) Very low calcium content of cochlear endolymph, an extracellular fluid. Nature 273:377-378.

Heidrych P, Zimmermann U, Kuhn S, Franz C, Engel J, Duncker SV, Hirt B, Pusch CM, Ruth P, Pfister M, Marcotti W, Blin N, Knipper M (2009) Otoferlin interacts with myosin VI: implications for maintenance of the 
basolateral synaptic structure of the inner hair cell. Hum Mol Genet 18:2779-2790.

Ikeda K, Morizono T (1989) Electrochemical profile for calcium ions in the stria vascularis: cellular model of calcium transport mechanism. Hear Res 40:111-116.

Johnson SL, Marcotti W (2008) Biophysical properties of $\mathrm{Ca}_{\mathrm{V}} 1.3$ calcium channels in gerbil inner hair cells. J Physiol 586:1029-1042.

Johnson SL, Adelman JP, Marcotti W (2007) Genetic deletion of SK2 channels in mouse inner hair cells prevents the developmental linearization in the $\mathrm{Ca}^{2+}$ dependence of exocytosis. J Physiol 583:631-646.

Johnson SL, Forge A, Knipper M, Münkner S, Marcotti W (2008) Tonotopic variation in the calcium dependence of neurotransmitter release and vesicle pool replenishment at mammalian auditory ribbon synapses. J Neurosci 28:7670-7678.

Johnson SL, Eckrich T, Kuhn S, Zampini V, Franz C, Ranatunga KM, Roberts TP, Masetto S, Knipper M, Kros CJ, Marcotti W (2011a) Positiondependent patterning of spontaneous action potentials in immature cochlear inner hair cells. Nat Neurosci 14:711-717.

Johnson SL, Beurg M, Marcotti W, Fettiplace R (2011b) Prestin-driven cochlear amplification is not limited by the outer hair cell membrane time constant. Neuron 70:1143-1154.

Kandler K, Clause A, Noh J (2009) Tonotopic reorganization of developing auditory brainstem circuits. Nat Neurosci 12:711-717.

Kros CJ, Rüsch A, Richardson GP (1992) Mechano-electrical transducer currents in hair cells of the cultured neonatal mouse cochlea. Proc Biol Sci 249:185-193.

Kros CJ, Ruppersberg JP, Rüsch A (1998) Expression of a potassium current in inner hair cells during development of hearing in mice. Nature 394:281-284.

Lelli A, Asai Y, Forge A, Holt JR, Géléoc GS (2009) Tonotopic gradient in the developmental acquisition of sensory transduction in outer hair cells of the mouse cochlea. J Neurophysiol 101:2961-2973.

Marcotti W (2012) 2011 Sharpey-Schafer Lecture: functional assembly of mammalian cochlear hair cells. Exp Physiol 97:438-451.

Marcotti W, Johnson SL, Ben-David O, Avraham KB, Kros CJ (2001) Electrophysiological properties of developing cochlear hair cells in Snell's waltzer mice. Paper presented at the 24th Annual Meeting of the Association for Research in Otolaryngology, abstract 358, St. Petersburg Beach, Florida, February $4-8$.
Marcotti W, Johnson SL, Holley MC, Kros CJ (2003a) Developmental changes in the expression of potassium currents of embryonic, neonatal and mature mouse inner hair cells. J Physiol 548:383-400.

Marcotti W, Johnson SL, Rüsch A, Kros CJ (2003b) Sodium and calcium currents shape action potentials in immature mouse inner hair cells. J Physiol 552:743-761.

Marcotti W, van Netten SM, Kros CJ (2005) The aminoglycoside antibiotic dihydrostreptomycin rapidly enters mouse outer hair cells through the mechano-electrical transducer channels. J Physiol 567:505-521.

Petit C, Richardson GP (2009) Linking genes underlying deafness to hairbundle development and function. Nat Neurosci 12:703-710.

Ricci AJ, Fettiplace R (1998) Calcium permeation of the turtle hair cell mechanotransducer channel and its relation to the composition of endolymph. J Physiol 506:159-173.

Rübsamen R and Lippe WR (1998) The development of cochlear function. In: Development of the auditory system (Rubel EW, Popper A, Fay R, eds), pp 193-270. New York: Springer.

Self T, Sobe T, Copeland NG, Jenkins NA, Avraham KB, Steel KP (1999) Role of myosin VI in the differentiation of cochlear hair cells. Dev Biol 214:331-341.

Spitzer NC, Lautermilch NJ, Smith RD, Gomez TM (2000) Coding of neuronal differentiation by calcium transients. Bioessays 22:811-817.

Tritsch NX, Yi E, Gale JE, Glowatzki E, Bergles DE (2007) The origin of spontaneous activity in the developing auditory system. Nature 450:50-55.

Wangemann P, Schacht J (1996) Homeostatic mechanisms in the cochlea. In: The cochlea (Dallos P, Popper A, Fay R, eds), pp 130-185. New York: Springer.

Wood JD, Muchinsky SJ, Filoteo AG, Penniston JT, Tempel BL (2004) Low endolymph calcium concentrations in deafwaddler2J mice suggest that PMCA2 contributes to endolymph calcium maintenance. J Assoc Res Otolaryngol 5:99-110.

Zampini V, Johnson SL, Franz C, Lawrence ND, Münkner S, Engel J, Knipper M, Magistretti J, Masetto S, Marcotti W (2010) Elementary properties of $\mathrm{Ca}_{\mathrm{V}} 1.3 \mathrm{Ca}^{2+}$ channels expressed in mouse cochlear inner hair cells. J Physiol 588:187-199.

Zilberstein Y, Liberman MC, Corfas G (2012) Inner hair cells are not required for survival of spiral ganglion neurons in the adult cochlea. J Neurosci 32:405-410. 